\title{
Editorial
}

\section{Are we having any impact?}

As the Editor of a scientific journal, there are many responsibilities that are both difficult and time consuming but necessary, such as the assessment of submitted manuscripts and the appraisal of referees' recommendations. In addition, there are some tasks that are inherently unpleasant and dissatisfying, such as having to inform enthusiastic researchers that their work is not suitable for publication because of unsuccessful peer review. However, there are also some benefits and occasional rewards associated with this role, such as the communication of good news. Hence, I am delighted to report in this issue that the impact factor of Acta Neuropsychiatrica has increased further and that its ranking amongst psychiatry journals continues to improve.

The merits and limitations of an index such as the impact factor have been much debated and clearly there are both advantages and disadvantages to the current means of rating and ranking journals. For instance, articles in high impact journals are not guaranteed higher citation and many influential articles that have clinical salience and scientific impact are published in journals without a high impact factor. Having said this, given the importance attached to impact factor within academia for reasons of promotion and funding, an article in a high impact factor journal is naturally more likely to attract attention and be desirable.

Reviewing the submissions to Acta Neuropsychiatrica over the past couple of years, in this context, it is apparent that the quality of manuscripts has noticeably improved. It is tempting to simply conclude that this is because of an increase in impact factor however, in reality the increase is marginal and the improvement modest, and it is therefore possibly too early to speculate a casual link. Nevertheless, irrespective of impact factor it is anticipated that as the journal gains popularity it will continue to attract important research articles and scholarly reviews $(1,2)$. The high quality of some of the submissions and the breadth of research that has been published in the journal thus far is aptly demonstrated by the original articles in this issue that collectively examine immune function, genes and behaviour (3-5). In addition, the detailed correspondence captured by the Comment and Critique section permits the publication of insightful clinical and research observations. This simple structure has provided a successful framework for the journal that is further enhanced by the unique special sections that highlight, on a bimonthly basis, new treatments, statistical methodologies, technological advances and contemporary clinical issues.

Finally, I am indebted to the many contributors, reviewers and assessors and in particular the editorial team that make this Journal possible and I am grateful to the publishers for the support and freedom they have afforded the Journal with respect to publishing scope and style.

Professor Gin S. Malhi

Discipline of Psychological Medicine Northern Clinical School The University of Sydney Sydney, NSW Australia

\section{Statement of disclosure}

Prof. Malhi has no conflicts of interest to declare in relation to this article.

\section{References}

1. Valenzuela M, Sidhu K, Dean S, Sachdev P. Neural stem cell therapy for neuropsychiatric disorders. Acta Neuropsychiatr 2007;19:11-26.

2. Ivanovski B, MaLhi GS. The psychological and neurophysiological concomitants of mindulness forms of meditation. Acta Neuropsychiatr 2007;19:76-91.

3. Vollmer-Conna U, Bird K, Yeo B, Truskett P, Westbrook R, Wakefield D. Psychological factors, immune function and recovery from major surgery. Acta Neuropsychiatr 2009;21:111-120.

4. Yonggui Y, You J, Shi Y, Zhiunn Z, Zhang X, Li H. Lack of association between the BDNF Val66Met gene polymorphism and late-onset depression in a Chinese Han population. Acta Neuropsychiatr 2009;21:128-132.

5. Venneri A, Gardini S, Caffara P. Decreased drugcue induced attentional bias in individuals with treated and untreated drug dependence. Acta Neuropsychiatr 2009;21:121-127. 